
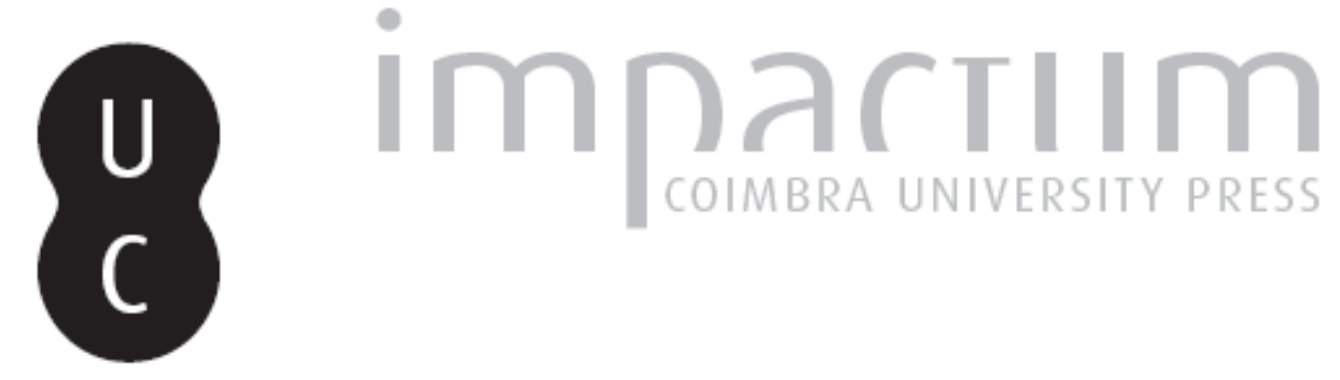

\title{
[Recensão a] Claude DOMERGUE, Les mines de la Péninsule Ibérique dans I'Antiquité romaine
}

\author{
Autor(es): $\quad$ Alarcão, Jorge de \\ Publicado por: Imprensa da Universidade de Coimbra \\ URL \\ persistente: \\ URI:http://hdl.handle.net/10316.2/45554 \\ DOI: \\ DOI:https://dx.doi.org/10.14195/1647-8657_29_12
}

Accessed : $\quad$ 26-Apr-2023 16:02:49

A navegação consulta e descarregamento dos títulos inseridos nas Bibliotecas Digitais UC Digitalis, UC Pombalina e UC Impactum, pressupõem a aceitação plena e sem reservas dos Termos e Condições de Uso destas Bibliotecas Digitais, disponíveis em https://digitalis.uc.pt/pt-pt/termos.

Conforme exposto nos referidos Termos e Condições de Uso, o descarregamento de títulos de acesso restrito requer uma licença válida de autorização devendo o utilizador aceder ao(s) documento(s) a partir de um endereço de IP da instituição detentora da supramencionada licença.

Ao utilizador é apenas permitido o descarregamento para uso pessoal, pelo que o emprego do(s) título(s) descarregado(s) para outro fim, designadamente comercial, carece de autorização do respetivo autor ou editor da obra.

Na medida em que todas as obras da UC Digitalis se encontram protegidas pelo Código do Direito de Autor e Direitos Conexos e demais legislação aplicável, toda a cópia, parcial ou total, deste documento, nos casos em que é legalmente admitida, deverá conter ou fazer-se acompanhar por este aviso.

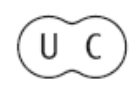


FACULDADE DE LETRAS

INSTITUTO DE ARQUEOLOGIA

CONIMBRIGA

VOLUME XXIX

UNIVERSIDADE DE COIMBRA

1990 
A inclusão de C. Turranius Rufus entre os magistrados municipais (inscrição 330) com o argumento de que, estando inscrito na tribo Quirina, deve ter recebido a cidadania através do exercício de uma magistratura local, devia ter logicamente levado o autor a incluir na sua lista muitas outras inscrições de cidadãos inscritos na mesma tribo.

Não temos provas de que $Q$. Talotius Allius Silonianus (inscrição 328) tenha sido magistrado municipal, mas apenas decurião de Collippo.

JORGE DE ALARCÃO

Claude DOMERGUE, Les mines de la Péninsule Ibérique dans TAntiquité romaine, Roma, 1990. Collection de l'École Française de Rome, 127. 1 vol., XX + 662 p., 32 estampas, 53 figuras e 6 mapas.

A riqueza da Hispânia em metais de toda a ordem foi louvada pelos autores antigos, gregos e latinos, desde Estesícoro (séc. VI a. C.) a Isidoro de Sevilha (séc. VII d. C.). As referências desses autores são todavia vagas e raramente se encontra neles menção de minas concretas. A partir de meados do séc. XIX, os trabalhos modernos de prospecção e de exploração mineiras, conduzidos por engenheiros cuja formação histórica era, no geral, razoável, levaram à descoberta de muitas minas antigas que somam hoje, segundo o Catalogue des mines et des fonderies antiques de la Péninsule Ibérique, publicado por C. Domergue em 1987, 565 sítios. Deduzido, na maior parte dos casos, de urna extensa bibliografia, aliás confirmada por incontáveis visitas aos locais, esse catálogo representa um excelente ponto da situação, com registo de lugares inéditos. Era todavia necessário completá-lo com uma síntese sobre a mineração romana da Península, nos seus aspectos técnicos, administrativos e económicos. A essa necessidade responde a obra agora editada. Com o catálogo dos lingotes, cuja publicação se anuncia, C. Domergue completará uma monumental trilogia que o acredita como investigador ímpar da mineração romana da Península Ibérica.

A primeira parte da obra é consagrada aos testemunhos dos autores antigos, às grandes linhas tectónicas da Península, aos grandes tipos de mineralização (jazidas em rocha ou jazidas detríticas), às grandes regiões mineiras e aos tipos de minérios explorados na Antiguidade.

$\mathrm{Na}$ segunda parte, o autor aborda a exploração mineira pré-romana desde as suas origens, num horizonte pré-campaniforme que se situa nos fins do quarto milénio a.C. Considera a hipótese de uma eventual descoberta autónoma da metalurgia do cobre na Península Ibérica, independentemente de quaisquer contactos com o Oriente; mas, prudentemente, não toma posição neste debate entre migracionistas e defensores de uma invenção ibérica autónoma.

Se, para o Calcolitico, é difícil citar minas (embora seja possível sugerir algumas áreas de mineração), os dados são mais abundantes e seguros para a Idade do Bronze: C. Domergue regista 128 jazidas concretas com materiais atribuíveis a este período. Muitas vezes, esses materiais são apenas os martelos feitos de seixos circundados por uma ranhura. Justifica-se, por isso, a discussão sobre a cronologia destes martelos, que o autor circunscreve à Idade do Bronze. 
Escrita aparentemente entre 1976 e 1979, esta segunda parte da obra não foi devidamente actualizada: assim, por exemplo, o inventário das datas de $\mathrm{C}^{14}$ detém-se em 1976; o autor parece ignorar a tendência actual para situar Tartesso em Huelva ou a datação que ora se defende para o depósito da ria de Huelva (séc. IX a. C.); considera Mainaké uma colónia grega, ignorando a hipótese de Niemeyer de identificar Mainaké com Toscanos.

Na terceira parte da obra, C. Domergue trata da mineração da época romana. Nos inícios do séc. II a. C. é evidente a exploração das minas do Sudeste (especialmente das de Carthago Nova) e de Cástulo; mas não temos provas de trabalhos nas minas de prata e cobre da Serra Morena ou nas de Riotinto, que provavelmente só foram exploradas no último terço do séc. II ou nos inícios do I a. C. Quanto a Aljustrel, a exploração não terá começado antes de meados do séc. I a. C. Teria sido interessante citar, neste contexto, as villae fortificadas do Baixo Alentejo estudadas por Manuel Maia, as quais parecem relacionadas com o aproveitamento de pequenos filões argentíferos. Pela mesma época poderá ter começado a exploração de ouro aluvionar no rio Alva, afluente do Mondego, se acaso o acampamento romano da Lomba do Canho (Arganil) se puder explicar como um posto de vigilância desses trabalhos. Na mesma região do Alva, os Furados de Pombeiro (POR 19), citados na p. 206, não são obra romana, mas construção mandada fazer no séc. XIV para movimentar um pisão e moinhos (Frias, David Correia Sanches de, Pombeiro da Beira. Memòria histórica e descriptiva, Lisboa, 1899, p. 27-28).

A época de Augusto parece ter sido sobretudo um período de prospecção das riquezas do Noroeste, recentemente conquistado; dos fins do seu reinado ou do tempo de Tibério dataria a abertura das grandes minas da Galiza, das Astúrias e do Norte de Portugal.

No séc. III d. C., muitas minas da Península Ibérica são abandonadas: de 173 minas registadas para o Alto Império, passa-se a 21 apenas para o Baixo Império. Talvez a lista deva ser acrescentada: moedas de Teodosio em S. Domingos (Mértola) sugerem a continuidade de exploração deste sítio. A quebra da mineração é todavia espectacular, explicável pela falta de mão-de-obra e pela concorrência das outras províncias do império romano. Talvez se devam considerar ainda, como sugere Edmondson, os efeitos da desflorestação, que terá trazido problemas de abastecimento dos fomos de fundição.

A administração das minas constitui o tema da quarta parte da obra. Examina-se em primeiro lugar o estatuto jurídico. As minas de propriedade particular teriam sido numerosas no período republicano; mas no séc. I a. C. e no I d. C., a maior parte das minas teria sido integrada no domínio público; e o autor conclui, embora com algumas reservas, pela inexistência de minas privadas a partir do séc. I d. C. Se bem que nos faltem dados literários ou epigráficos para resolver de modo satisfatório o problema, parece-nos improvável que todas as minas, mesmo as mais pequenas, tenham sido propriedade pública. As grandes minas de ouro, prata e cobre terão sido metalla publica; mas muitas pequenas minas de cobre e sobretudo de ferro devem ter sido sempre propriedade privada.

O regime administrativo das minas na época republicana e no período imperial constitui objecto de densos capítulos em que os textos literários e epigráficos são profundamente explorados.

A quinta parte da obra trata de aspectos sociais e económicos: a condição jurídica e social dos concessionários das minas, a sua origem (muitos itálicos), a composição da mão-de-obra, a vida quotidiana dos mineiros (descrita em páginas extraordinariamente vivas), a importância da produção e o seu lugar na economia do mundo romano. A lista

Conimbriga, 29 (1990), 147-194 
das inscrições funerárias de Três Minas (Portugal) deve ser completada (cfr. Madrider Mitteilungen, 29, 1988, p. 239).

A última parte é consagrada a aspectos técnicos: instrumentos usados nas minas, processos de desmonte, meios de elevação do minério até à superfície, processos de entivação, meios de acesso às minas, processos de evacuação das águas, etc. Nos dois últimos capítulos, o autor ocupa-se das minas a céu aberto e do tratamento do minério.

Fruto de muitos anos de labor, obra de um arqueólogo cuja familiaridade com os autores clássicos vai a par com profundos conhecimentos de geologia e de mineralogia, este trabalho de C. Domergue é uma excelente síntese da mineração na Península Ibérica.

JORGE DE ALARCÃo

\section{SUPPLEMENTA ITALICA, 3 (nuova serie). Edizioni Quasar, Roma, 1987. 240 pp. ISBN} $88-85020-84^{\wedge} 1$.

Publicado com o contributo do Consiglio Nazionale delle Ricerche italiano, o volume tem apresentação de Margherita Guarducci e Silvio Panciera, responsáveis por parte do projecto, em curso, de revisão dos monumentos epigráficos romanos da Itália.

Após referirem as dificuldades financeiras que atrasaram um pouco a edição, aludem às outras iniciativas itálicas no âmbito epigráfico. $\mathrm{O}$ primeiro dos suplementos abarcou três cidades: Ferentinum, Pisaurum e Falerii Novi; o segundo, quatro centros: Velitrae, Histonium, Teate Marrucinorum e Vada Sabatia. O terceiro abrange, agora, oito cidades: da Regio III (Lucania et Brutti), Locri, cuja epigrafia Marco Buonocore estudou; Tegianum, Cosilinum, Atina, Volcei e Eburum, a cargo de Vittorio Braco; da Regio IV (Sabina et Samnium), Corfinium, por M. Buonocore; finalmente, da Regio IX (Liguria), a Luna ad Genuam, da responsabilidade de Giovanni Mennella.

O esquema adoptado em cada capítulo foi o seguinte: as colectâneas que se actualizan!; a bibliografia epigráfica; outra bibliografia essencial; adenda e corrigenda às notícias históricas dadas pelas colectâneas a actualizar. Vêm, em seguida - e esta é a parte mais importante e densa do trabalho - os aditamentos e correcções aos monumentos epigráficos incluídos nos corpora actualizados. Páginas bem recheadas, sem divisão em parágrafos para poupar espaço. Os textos vêm identificados com os números originais, a negro; apenas se deixa um centímetro em branco para mais nítida separação. É compreensível o esquema adoptado, numa época em que o factor económico se impõe como fundamental. Não poderemos esquecer, porém, que o volume se destina a servir primordialmente como livro de consulta; nesse caso, toma-se difícil saber, por exemplo, que CIL X 21 teve nova leitura na p. 17 ou que CIL X 33 continua perdida. A existência de índices analíticos nas pp. 35-36, relativos aos monumentos epigráficos de Locri, não serão inúteis monograficamente mas de pouco interesse prático resultam, uma vez que falta, no final do livro, um índice geral que os refira. O ideal teria sido, em meu entender, optar-se por uma fórmula que tudo reunisse no fim, com indexação da página e não da epígrafe.

Termina cada capítulo pela indicação dos "novos textos", ou seja, daqueles que foram publicados após a edição dos corpora que ora aqui se actualizam. Apresenta-se, de cada um, breve síntese que compreende: descrição sumária, dimensões, lugares de achado e paradeiro, bibliografia, leitura, fotografia e sumaríssimo comentário (a referir, v.g., questões onomásticas, históricas e a datação proposta).

Conimbriga, 29 (1990), 147-194 